\title{
Mainstreaming Early Warning Systems in Development and Planning Processes: Multilevel Implementation of Sendai Framework in Indus and Sahel
}

\author{
Asim Zia ${ }^{1,2} \cdot$ Courtney Hammond Wagner ${ }^{3}$
}

Published online: 18 June 2015

(c) The Author(s) 2015. This article is published with open access at Springerlink.com

\begin{abstract}
The third UN World Congress on Disaster Risk Reduction, held in Sendai, Japan in March 2015, agreed on a new framework to guide disaster risk reduction policy and practice for the next 15 years. The Sendai Framework for Disaster Risk Reduction 2015-2030 (SFDRR) leaves important implementation issues unspecified and potentially creates both problems and opportunities for complex, multilevel governance systems in coping with hazards and disastrous events. Early warning systems (EWS), if built into the mainstream of planning for development and disaster relief and recovery, could present a significant opportunity to realize many SFDRR goals. We explore the complexities of using hydrometeorological EWS to prepare for drought and flood disasters in the densely populated communities of Pakistan's Indus River Basin in contrast to the African Sahel's less densely settled grasslands. Multilevel governance systems are often dominated by a topdown, technocentric, centralized management bias and have great difficulty responding to the needs of peripheral and vulnerable populations. People-centered, bottom-up approaches that incorporate disaggregated communities with local knowledge into a balanced, multilevel disaster risk management and governance structure have a
\end{abstract}

Asim Zia

Asim.Zia@uvm.edu

1 Department of Community Development and Applied Economics, University of Vermont, Burlington, VT 05405, USA

2 Department of Computer Science, University of Vermont, Burlington, VT 05405, USA

3 Rubenstein School of the Environment and Natural Resources, University of Vermont, Burlington, VT 05405, USA dramatically better chance of realizing the SFDRR goals for disaster risk reduction.

Keywords Early warning systems - Infrastructure development $\cdot$ Land-use planning $\cdot$ Policy implementation $\cdot$ Risk governance $\cdot$ Sendai Framework $\cdot$ Science-policy interface

\section{Introduction}

The Sendai Framework for Disaster Risk Reduction 2015-2030 (SFDRR) (UNISDR 2015), recently negotiated in the United Nations International Strategy for Disaster Reduction (UNISDR) conference in Sendai, Japan, replaces the Hyogo Framework for Action 2005-2015 (HFA) (UNISDR 2005) as a guiding policy document to steer disaster risk governance. Although the Hyogo Framework for Action was able to bring disaster risk reduction (DRR) to the attention of international and national development agencies for investment priorities, the effectiveness of HFA in "bending" the disaster damage curve remains to be seen. During 2005-2015 "over 700000 people lost their lives, over 1.4 million were injured and approximately 23 million were made homeless as a result of disasters. Overall, more than 1.5 billion people were affected by disasters in various ways. Women, children and people in vulnerable situations were disproportionately affected. The total economic loss was more than $\$ 1.3$ trillion. In addition, between 2008 and 2012, 144 million people were displaced by disasters" (UNISDR 2015, p. 4). Many regional and global scale studies suggest increases in exposure to hydrometeorological hazards, in particular from climate change-induced alterations in the frequency, intensity, and extent of extreme events (IPCC 2012). Coupled with other social and 
economic drivers of vulnerability, these changes could amplify risk and damages. The SFDRR sets out four priority actions to counter this trend: (1) understanding disaster risk; (2) strengthening disaster risk governance to manage disaster risk; (3) investing in disaster risk reduction for resilience; and (4) enhancing disaster preparedness for effective response, as well as to "Build Back Better" in recovery, rehabilitation, and reconstruction.

The SFDRR acknowledges that "overall, the Hyogo Framework for Action has provided critical guidance in efforts to reduce disaster risk and contributed to the progress towards the achievement of the Millennium Development Goals. Its implementation has, however, highlighted a number of gaps in addressing the underlying disaster risk factors, in the formulation of goals and priorities for action, in the need to foster disaster resilience at all levels and in ensuring adequate means of implementation" (UNISDR 2015, p. 5, author bold). In the light of the third identified gap in SFDRR, this article addresses the question: Does SFDRR provide better "means of implementation" for multilevel governance systems than HFA? Without appropriate "means of implementation," that is a risk governance system, a framework would not be expected to lead to changes in disaster risk reduction outcomes. Both multilevel risk governance and resource/investment allocations are critical components for delivering the "means of implementation" of a policy/framework.

Despite the many DRR strategies that could be assessed for SFDRR implementation, this study focuses on an emerging opportunity that pertains to the mainstreaming of hydrometeorological early warning systems (EWS) as a DRR strategy in development and land-use planning processes across multiple levels of governments. The SFDRR endorses the use of multihazard EWS as a sound disaster risk reduction investment strategy and promotes the incorporation of disaster risk reduction in development and planning processes across developed and developing countries. One of the major goals declared in SFDRR is to "substantially increase the availability of and access to multi-hazard EWS and disaster risk information and assessments to the people by 2030" (UNISDR 2015, p. 8). Further, SFDRR declares under Priority 3 (investing in disaster risk reduction for resilience) that both national and local level government agencies must "(f) promote the mainstreaming of disaster risk assessments into land-use policy development and implementation, including urban planning, land degradation assessments and informal and non-permanent housing, and the use of guidelines and follow-up tools informed by anticipated demographic and environmental changes" and " $(\mathrm{g})$ promote the mainstreaming of disaster risk assessment, mapping and management into rural development planning and management of, inter alia, mountains, rivers, coastal flood plain areas, drylands, wetlands and all other areas prone to droughts and flooding, including through the identification of areas that are safe for human settlement and at the same time preserving ecosystem functions that help reduce risks" (UNISDR 2015, p. 15).

Effectively designed hydrometeorological EWS, which are integrated with institutional mechanisms at multiple levels of governance, have the potential to both mitigate the impacts of and increase resilience to hydrometeorological induced flood and drought risks. Mainstreaming climate impact forecast information into land-use planning and infrastructure development processes can enhance sustainable development and mitigate the medium- to longterm risk from climate change as a proactive adaptation intervention (Zia 2012). In the broader context of adaptation to climate change, effective integration of EWS with institutional and policy-design processes have the potential to increase the resilience and decrease the vulnerability from hydrometeorological related risks. This potential, however, needs to be tested/implemented in the field with real-time integration of EWS with policy and planning processes.

EWS could be deployed for a variety of natural hazards including sudden-onset events such as earthquakes, tsunamis (Taubenböck et al. 2009; Liu et al. 2009; Thomalla and Larsen 2010; Spahn et al. 2010), landslides (Intrieri et al. 2012), and flooding from rivers and tsunamis (Basher 2006; Thieler et al. 2009) as well as more gradual processes like drought (Pozzi et al. 2013; Pulwarty and Sivakumar 2014) and malaria transmission that result from climate variability (Thomson et al. 2006). As such, the hazards for which EWS are established to mitigate can act on a multitude of temporal and spatial scales. The temporal scales (early warning lead times) range from minutes in the case of earthquake and tsunami, to hours in the event of river flooding, and at times months and even years in the case of drought. For more gradual processes, for instance drought and desertification, a different kind of sustainable hydrometeorological EWS is required to monitor slow onset, incremental but accumulative changes, for example, creeping environmental change (Glantz 1999). Climate change-driven forecasts under alternate scenarios, or representative concentration pathways (RCPs), can generate medium to long-term forecasts.

Though replete with "dos" and "don'ts," the SFDRR lacks any specific guidance on the means of implementation of proposed DRR strategies, in particular the integration of EWS with development and planning processes across multiple scales of governance from local to regional, national, and international administrative units. Both Priority 2 and 3 contain general framework guidelines that could be used to infer different risk governance and mainstreaming scenarios in specific country-wide or 
continent-wide contexts. Under Priority 2 (strengthening disaster risk governance to manage disaster risk), the SFDRR vision of a multilevel risk governance is replete with contradictions. Implementation is caught between donor and national government controlled top-down governance mechanisms as opposed to people- and community-centered risk governance. Similarly, under Priority 3 (investing in disaster risk reduction for resilience), vague policy and programming guidelines are provided for the Organisation for Economic Co-operation and Development (OECD) and other bilateral and multilateral donor countries with which they are expected to generate investment resources for DRR strategies, such as the mainstreaming of DRR in development processes or better integration of EWS in end-user decision making processes; however, there are no specific mandatory requirements for allocation of DRR investments in OECD or other financial mechanisms. Within countries, in particular in developing countries, lack of investment funding and adaptive capacity poses perilous challenges to prepare and plan for implementation of a climate-resilient development and land-use planning agenda. Lack of specific guidance on multilevel risk governance mechanisms as well as mandatory investment/funding allocations makes it hard to believe that over the next 15 years SFDRR will be able to overcome the "means of implementation" challenges that have emerged as an important gap as a result of HFA implementation in 2005-2015.

The implementation of the UNISDR recommended approach to EWS under HFA identified a range of policy and governance challenges. The UNISDR proposes development of four elements of weather-based EWS that encompass risk knowledge, monitoring and warning services of risk, dissemination and communication of the risk information, and the capability of response (Basher 2006). A fundamental aspect within the UNISDR elements is the incorporation of local knowledge and integration of the EWS into the daily life, awareness, and ontologies of the local population. In this vein, the UNISDR framework could be employed to mitigate and minimize the impact of extreme flood events in large hydrological watersheds like the lower Mekong River as well as smaller basins (Plate 2007; Ardalan et al. 2009; Alfieri et al. 2012; Fakhruddin 2014). Utilizing UNISDR EWS as a baseline framework in the case of floods and droughts could potentially reduce the impact and effects of such gradual processes, but the integration of hydrometeorological EWS with end-user decision making and planning processes still poses fundamental challenges (Kelman and Glantz 2014).

In Sect. 2 of this article, the SDFRR "means of implementation" challenges are illustrated in the context of mainstreaming hydrometeorological EWS in the development and land-use planning processes in the Indus Basin and the Sahel region of Africa. In both regions, human activities and anthropogenic climate change pose enormous water and food-security related challenges, as well as benefits and opportunities for action. Further, this section focuses on the potential of EWS in mainstreaming DRR in development and planning processes that has not been realized, at least in the Indus Basin and Sahel regions as it was expected in the landmark Hyogo Framework for Action. In Sect. 3 we assess the tension/ambiguity between "technocentric" and "top-down" versus "people-centered" and "bottom-up" risk governance approaches for implementation of the DRR strategies negotiated in Sendai. In the context of the case study areas, we investigate why practical implementation of EWS since HFA has remained skewed towards technical/top-down investments in improving the monitoring and forecasting capabilities of EWS, and less emphasis has been placed on incorporating the risk perceptions and decision making of the EWS endusers in designing and communicating early warnings. Although the Sendai Framework, compared with HFA, emphasizes a "people-centered," "bottom-up" shift in broad risk governance, the underlying funding and institutional mechanisms (Priority 3 in SFDRR) appear to assume a technocentric, top-down implementation of DRR strategies. This focus is particularly true in the generation and allocation of financial and technical resources for investments in developing EWS and mainstreaming DRR in development. Finally, in Sect. 4 we develop an argument that UNISDR and relevant implementation parties need to strike a balance between top-down/technocentric and bottom-up/people-centered implementation approaches for SFDRR in a multilevel risk governance context.

\section{SFDRR and DRR: Case Studies of Implementation Challenges}

Climate change presents special challenges for disaster risk reduction. The best places to examine those problems are found in difficult environments where livelihoods are particularly vulnerable. We choose two dryland environments, the Indus River Basin of Pakistan and the transitional semiarid grasslands of the African Sahel, as the focus of our exploration of how complex and difficult realizing the goals of the SFDRR may be.

\subsection{Indus Basin}

The Indus Basin's millions of inhabitants are vulnerable to the formidable combination of societal vulnerabilities and climate change. It is expected that climate change will significantly affect the behavior and severity of naturally occurring hazards, such as floods, droughts, heat waves, 
and cyclones, sometimes increasing their frequency and intensity and sometimes decreasing them (IPCC 2012, 2014). In addition to the added uncertainty in the occurrence of natural meteorological hazards, the Indus Basin has a major concern in the expected melting of Himalayan glaciers. The increase in glacial melt will severely disturb the hydrometeorological cycle of the Indus River system, an essential source of food and water for millions of people (Immerzeel et al. 2010; Zia 2013). Superimposed on the natural hazards is the plethora of increasing societal vulnerabilities: rising populations of mostly homeless poor people, rural to urban migration (Mustafa and Sawas 2013), the growth of urban and suburban slums (Marx et al. 2013), financial volatility, economic insecurity, energy shortages (Komal and Faisal 2015), lack of human rights and law enforcement, political instability within country borders as well as across international borders, and ongoing ethnic, civic, linguistic, and religious proxy wars (Zia and Hameed 2014).

In this context of societal vulnerability, it is not surprising that breakdowns of disaster management strike almost every year in one of the Indus Basin countries, in particular Pakistan and Afghanistan. Figure 1 shows the international boundaries of the Indus Basin. The 2010 floods in upper and later on in lower Indus affected more than 18 million people, caused 1985 deaths, and damaged or destroyed 1.7 million houses; and hypothetically increased the influence of extremist organizations in the flood affected areas, though the State and civil society were able to retain political control in the short run (Hasan and Zaidi 2012). It is important to note that extremism in Pakistan, which was initially clustered around tribal areas in the upper Indus Basin, has recently increased in southern, lower Indus, areas (Javid 2011). Hasan and Zaidi (2012, p. 336) astutely note the impact of the 2010 floods on extremism in the short and long run: "Much of the damage caused by the recent flood has damaged the regions under manipulation and influence of the religious fundamentalists, and Pakistan's government has been sustaining pressures of the Western world to continue onslaught on this region, as these areas have been said to provide safe heaven for Al-Qaeda and other terrorist groups. Although with the support of the people, civil society and army, it could be argued that the situation has not adequately allowed insurgents to take a major political lead however it could still lead to future political unrest. The flooding effect could still trigger massive resentment against present regime; political resiliency also has to lock horns with multiple challenges in the shape of ongoing insurgencies, ever disturbing urban sectarian dissension, frightening suicide bombings in opposition to central institutions, economic weakening and regional political issues." Drought, another hydrometeorological hazard, also regularly afflicts the region. Unless systematic approaches to vulnerability reduction, early warning communication systems, and institutional mechanisms to cope with disasters through changes in land-use planning and economic development are pursued in advance, the adverse outcomes from natural hazards will increase in their severity and frequency according to human-induced climate change scenarios developed by IPCC (2014).

Climate change is expected to shift the spatial and temporal distributions of precipitation from the summer monsoon over the Indus River Basin. Increased greenhouse gas concentrations are expected to increase both the land-water temperature contrast and absolute temperature of the oceans, strengthening the monsoon (Turner and Annamalai 2012). Yet this expected trend has not been observed. Turner and Annamalai (2012) found that since 1950 the amount of rainfall produced by the South Asian summer monsoon has been decreasing and shifting eastward. An important caveat is that aerosols have been increasing over the region, and could be responsible for mitigating expected increasing trends (Ramanathan et al. 2005). While average observed seasonal precipitation resulting from the South Asian summer monsoon has decreased over the past six decades, an analysis by Singh et al. (2014) found historical shifts in extreme wet and dry spells. Specifically, peak-season precipitation has decreased while daily precipitation variability has increased, and the frequency of dry spells has increased while the intensity of dry spells has decreased (Singh et al. 2014). Projections of the South Asian summer monsoon by global climate models (GCMs) are mixed and dominated in the near-term by decadal variability. Ueda et al. (2006) found increasing seasonal precipitation despite a weakening of the monsoonal circulation, and Turner and Annamalai (2012) found a range of responses from unchanged to increased seasonal precipitation.

Uncertainties about monsoon variability and glacial melt timing pose enormous planning and policy challenges for the Indus Basin. The Indus Basin is a breadbasket for millions of people across the subcontinent, yet glacial melt and monsoon variability threatens the future of food production in its catchment regions. Effective water and food management policies require proactive land-use planning that is shaped by high resolution climate and hydrometeorological forecasts at all possible lead times, ranging from daily and weekly to annual and decadal. Integration of these forecasts into agency and individual decision-making processes is another critical need for effectively building adaptive capacity and resiliency in the basin. Both the generation and integration of climatological and hydrometeorological forecasts with decision making and planning processes require significant changes in current governance practices and resource allocations that affect the evolution of land-use development pathways. 


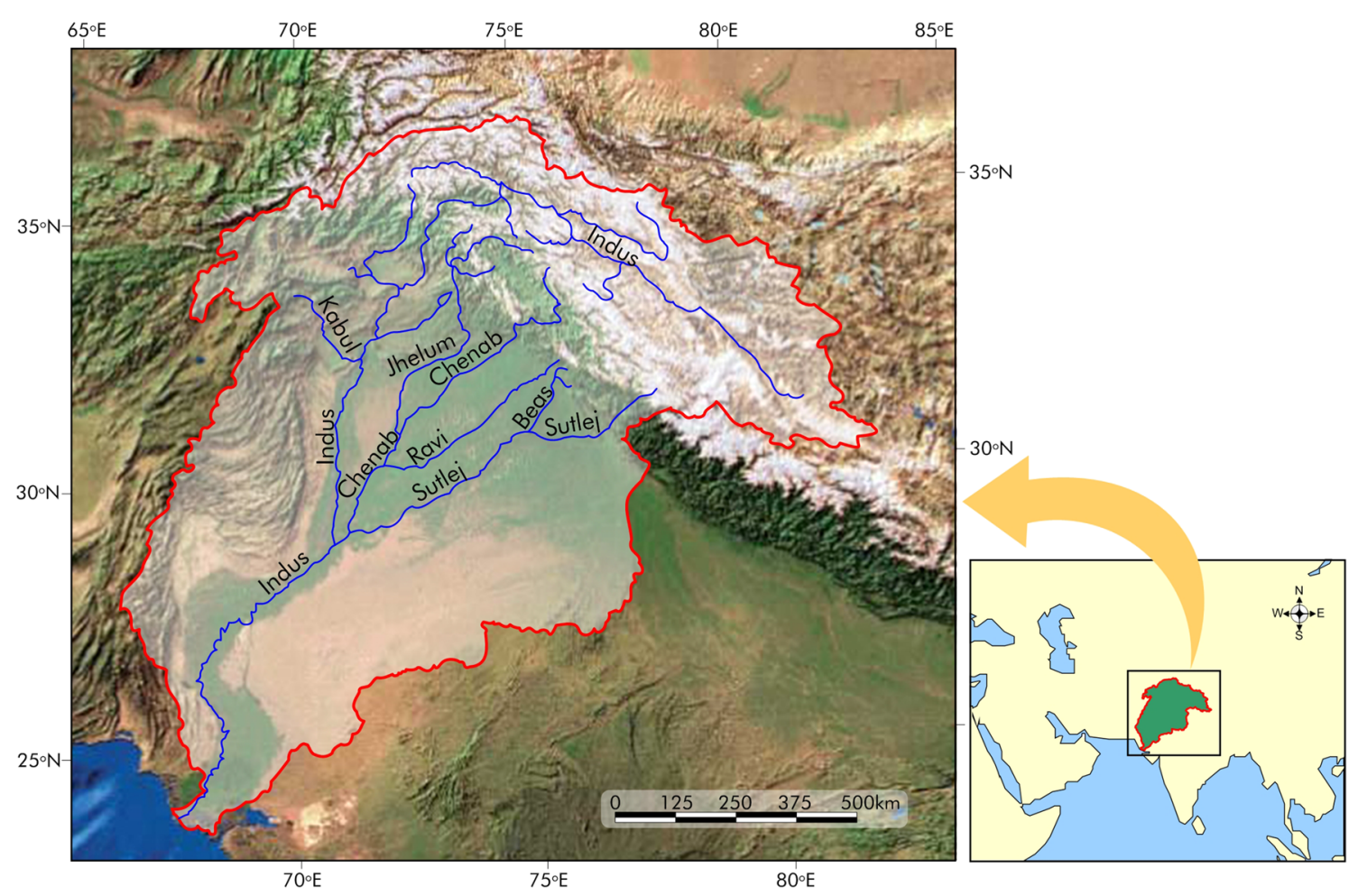

Fig. 1 Indus River Basin Source ICIMOD. Reprint with permission of ICIMOD

In earlier work in the Indus Basin, Zia and Glantz (2012), based upon multiple stakeholder workshops with local policy-making and planning agencies, scientists, and civil society organizations, identified a range of policy and governance challenges for designing resilient risk management and land-use planning approaches. Policies such as the introduction of flood insurance programs or governance of multihazard "risk zones" do not lend themselves to "linear" policy solutions as the SFDRR appears to assume. Mere injection of donor grants and soft loans in building technologically advanced EWS do not necessarily result in the introduction of climate resilient policy and planning processes. Rather, the climatological and hydrometeorological information is added to a mix of power struggles in rapidly globalizing societies such as Pakistan, India, and Afghanistan. Land grabs and related power struggles, on top of weak executive and judicial institutions, can leave such EWS forecasts as mere pieces of paper, waiting meaningful incorporation into agency or individual decision making. The "means of implementation" gap identified as a result of the HFA experiment will have similar political and governance challenges when the time comes to implement SFDRR. The potential of climatological and hydrometeorological EWS as a strategy for positioning DRR in development and planning processes has not yet been realized in the Indus Basin. But a fresh and novel way to conceptualize the SFDRR "means of implementation" could provide a transformational shift in business as usual top-down governance and resource allocation scenarios. Explicit focus on multilevel risk governance regimes with transparent and accountable participation and empowerment of local scale communities, in particular vulnerable communities, will need to be prioritized in SFDRR-driven investments, programs, and projects.

\subsection{Sahel Region}

Much like in the Indus Basin, in the Sahel region of Africa (Fig. 2) climate change is likely to work in tandem with societal vulnerabilities to produce both direct and indirect negative effects on the food security ${ }^{1}$ (IPCC 2012). In the relatively drier areas of the Sahel, food crop production is marginal or not viable due to a modest size, annually variable soil moisture store with which to sustain plant growth, high rainfall variability (skewed to dryness), and frequent occurrence of severe prolonged multiyear droughts (Glantz 1992; Rosenzweig et al. 2001; Challinor et al. 2007). Under a changing climate, severe regional droughts have become more frequent. Funk et al. (2008) concluded that the tendency for main growing season

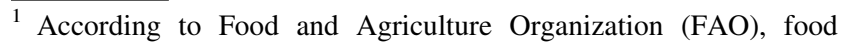
security exists when all people, at all times, have physical, social, and economic access to sufficient, safe, and nutritious food that meets their dietary needs and food preferences for an active and healthy life.
} 
Fig. 2 Sahel eco-region boundaries across Africa Data sources The Nature Conservancy, 2011. tnc_terr_ecoregions (vector digital data). Source data available at http://maps.tnc.org/ gis_data.html; Metadata available at http://maps.tnc.org/files/ metadata/TerrEcos.xml

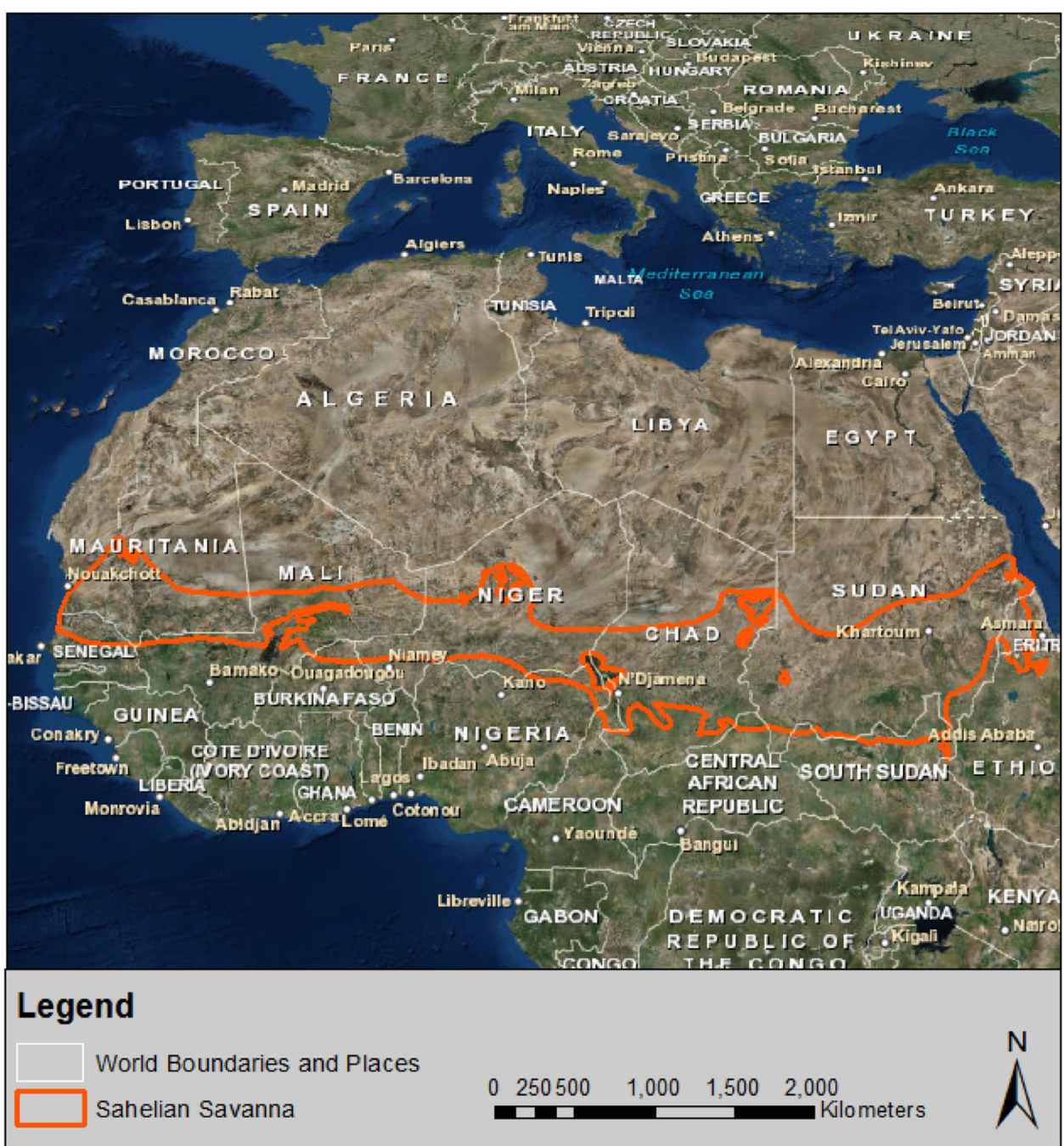

rainfall to decline has already contributed to food insecurity in eastern and southern Africa. Additionally, the expanded ranges of crop pests and altered transmission dynamics of insect pests and plant diseases predicted by climate change will likely exacerbate food availability problems in the Sahel countries (Rosenzweig et al. 2001). Not only can climate change be a significant factor that could undermine food security in Africa, but also ecosystem degradation, population growth, poor governance systems, low adaptive capacity, and economic decline has and will also likely contribute to continuing food insecurity in the Sahel region (Challinor et al. 2007; Funk et al. 2008; Bohle et al. 1994; Brown et al. 2007). The high sensitivity of food crop systems in Africa to climate is also exacerbated by constraints such as a heavy disease burden, conflicts and political instability, debt burden, and an unfair international trade system (Challinor et al. 2007). Therefore integration of climatological and hydrometeorological EWS in land-use and food planning processes could potentially yield considerable benefits in the Sahel region of Africa.

Relatively modest adverse changes in economies imply critical shifts in food security for those social groups that are currently vulnerable (Bohle et al. 1994). For example, the association between El Niño events and famines that killed tens of millions across the tropics in the late nineteenth century has been well documented. Davis (2002) argues that in the case of El Niño famine was triggered by drought, but was caused by the way political and economic colonization deprived people of their entitlements to natural resources. In contrast, droughts and famine can also bring many communities together in times of hardship and reduce conflict. The pathways in the exchange and political economies that ameliorate or mitigate the effects of climate change will probably have the more dominant effect on vulnerable individuals, groups, and classes in the Sahel region as well (Bohle et al. 1994). In addition, according to Challinor et al. (2007), whether the increasing demand for 
food due to population rise will be met primarily by extensification or intensification depends on land suitability and on the yield attainable from that land, as well as on the growth of national economies and of income-driven effective demand for food in the Sahel. Yields in Africa remain amongst the lowest in the world: in sub-Saharan regions, for example, mean rainfed cereal yields are 0.8 tons/ha, which is 0.4 tons/ha below the lowest figure for any other region. During the past 50 years, some $60 \%$ of the growth in cereal output in Africa has been from area expansion and $40 \%$ from yield increase (Challinor et al. 2007). Given the threefold expected increase in population by the end of this century, African Sahel countries cannot afford to be complacent about addressing the growing challenge of food security and sustainability as land use expansion and intensification accelerate against the background of increasing vulnerability to climate change.

In this context, the institutionalization of medium to long-term drought early warning forecast systems and their mainstreaming with land-use planning processes can provide a very useful science-policy interface in the Sahel countries. In particular, comparison of intensive agriculture versus agroecological land-use development pathways to produce a sustainable and equitable system would avoid worst-case food insecurity challenges brought about by climate change. Currently, there are a number of international, regional, and national EWS operating in the Sahel region. But in general these systems lack multilevel integration and national support and networks for local-level dissemination of information (Bailey 2013). At the international level, the Food and Agriculture Organization's Global Information and Early Warning System on Food and Agriculture (GIEWS), the World Food Program's Humanitarian Early Warning Service (HEWS), and the USAID Famine Early Warning System Network (FEWS Net) collectively monitor the whole of the Sahel region and produce monthly reports, bulletins, and drought status updates (Pulwarty and Sivakumar 2014). International level monitoring systems target national level decisionmakers and international support with the expectation that once the warning is issued aid will cascade down to the local community level. But in an analysis of the FEWS Net coverage of the 2007 floods in the Sahel region, Samimi et al. (2012) question the reliability of the information produced for emergency conditions at the regional and local scale because of the reliance on quick, standardized estimates.

At the regional level, the Inter-State Committee for Drought Control in the Sahel (CILSS) collects regional level monitoring data from the Agrometeorology, Hydrology, Meteorology (AGRHYMET) center in Niger, and creates a forum to connect national level decision-makers (Traore et al. 2014). The CILSS EWS was established in the 1970s and has made great advances in regional monitoring and capacity building, but the AGRHYMET monitoring system still faces issues of data acquisition from countries, limited observation points, and less than rapid transfer of data to monitoring organizations (Traore et al. 2014). Finally, individual states in the Sahel region have varying operational levels of monitoring and EWS. Niger and Ethiopia both have relatively long standing EWS, housed in government agencies that regularly collect local level monitoring data to pass up the administrative hierarchy to national level decision-makers, whereas Mauritania, Gambia, and Chad have either no national EWS or very limited EWS capacity (Bailey 2013). National and regional level EWS rely on local observations and monitoring stations, but there is a lack of structured and integrated systems of communication that disseminate information out to local communities beyond the trickle down of policy and international aid.

One recent attempt to fill this integration gap is a partnership between the Rainwatch initiative by the University of Oklahoma and the African Climate Exchange (AfClix), a UK-based boundary organization. Boundary organizations, such as AfClix, sit at the science-policy interface and by design, involve and are accountable to actors from both side of the interface (Guston 2001). The Rainwatch initiative is producing near real-time monitoring from a series of stations in Niger, which is made available to government officials, but the partnership with AfClix has opened up channels for two-way dialogue on the ground through partnerships with humanitarian and development decisionmakers in the region (Boyd et al. 2013). The Rainwatch/ AfClix partnership offers a glimpse into what a more collaborative science-policy interface could look like, integrating bottom-up, people-centered initiatives with topdown decision-making.

\section{Tension Between "Technocentric" and "Top- Down" Versus "People-Centered" and "Bottom-Up" Risk Governance Approaches}

Developing countries, especially South Asian and African Sahel societies, are extremely vulnerable to climatic shifts (Glantz and Adeel 2000; Glantz 2003; van Aalst 2006; Zia and Glantz 2012; Zia 2013; IPCC 2014). Vulnerabilities accrue from causes such as rising poverty, non-flexible sources of livelihood, poor disaster management, and the lack of long-term risk governance. Amidst this complex social, economic, and political context, the implementation of SFDRR can neither be done through a linear sciencepolicy interface, nor through a top-down, technocratic, controlled allocation of investments and resources. A closer analysis of SFDRR, however, reveals that it is beset 
with this top-down/technocratic and bottom-up/peoplecentered tension.

SFDRR for example tries to present both perspectives: "... in order to reduce disaster risk, there is a need to address existing challenges and prepare for future ones by focusing on: monitoring, assessing and understanding disaster risk and sharing such information and how it is created; strengthening disaster risk governance and coordination across relevant institutions and sectors and the full and meaningful participation of relevant stakeholders at appropriate levels; investing in the economic, social, health, cultural and educational resilience of persons, communities and countries and in the environment, also through technology and research; enhancing multi-hazard EWS, preparedness, response, recovery, rehabilitation and reconstruction" (UNISDR 2015, p. 6). In the following paragraph, SFDRR acknowledges that people-centered risk governance must be prioritized over simple monitoring type of mechanisms: "While some progress in building resilience and reducing losses and damages has been achieved, a substantial reduction of disaster risk requires perseverance and persistence, with a more explicit focus on people and their health and livelihoods, and regular followup" (UNISDR 2015, p. 6). Another plea for people-centered risk governance is echoed in SFDRR: "There has to be a broader and a more people-centred preventive approach to disaster risk. Disaster risk reduction practices need to be multi-hazard and multisectoral based, inclusive and accessible in order to be efficient and effective. While recognizing their leading, regulatory and coordination role, Governments should engage with relevant stakeholders, including women, children and youth, persons with disabilities, poor people, migrants, indigenous peoples, volunteers, the community of practitioners and older persons in the design and implementation of policies, plans and standards" (UNISDR 2015, p. 5).

Notwithstanding many other similar calls for peoplecentered DRR and risk governance, when it comes to mobilizing investments and resources, both international donor agencies and national governments are called to action that reflects a top-down/technocratic type of mindset in framing the risk governance. Consider this SFDRR statement: "The pursuance of this [DRR] goal requires the enhancement of the implementation capacity and capability of developing countries, in particular the least developed countries, small island developing States, landlocked developing countries and African countries, as well as middle-income countries facing specific challenges, including the mobilization of support through international cooperation for the provision of means of implementation in accordance with their national priorities" (UNISDR 2015, p. 7). In the same, SFDRR (UNISDR 2015, p. 8) frames proposition that EWS must be made available and accessible to the people, notwithstanding the fact that mere availability and accessibility of forecast information does not necessarily change the decision-making processes of vulnerable individuals and communities (as ample evidence has shown with respect to the use and value of forecast information-related research, for example Katz and Murphy (1997)).

Another example of top-down state centric risk governance is found in the following set of guidelines (UNISDR, p. 8): “(a) each State has the primary responsibility to prevent and reduce disaster risk, including through international, regional, subregional, transboundary and bilateral cooperation. The reduction of disaster risk is a common concern for all States and the extent to which developing countries are able to effectively enhance and implement national disaster risk reduction policies and measures in the context of their respective circumstances and capabilities can be further enhanced through the provision of sustainable international cooperation; (b) disaster risk reduction requires that responsibilities be shared by central Governments and relevant national authorities, sectors and stakeholders, as appropriate to their national circumstances and system of governance." Assigning primary responsibility at the state level belies the fact that many minority and vulnerable populations in south Asian and African Sahel countries are in fact in a state of proxy or actual wars against their state governments, be those Pashtun/Taliban fighting against Pakistan and Afghan national governments, or rebels in Mali or Sudan. In such situations, state governments are actively engaged in providing mis- or disinformation to such rebels as opposed to providing early forecast information about droughts and floods. Further, in many transboundary cases, state governments do not necessarily provide the best means to promote international or even regional cooperation. In the case of the Indus Basin, for example, the highland/upstream forecasting of the hydrometeorological system can be drastically improved if the glacial melt and stream-flow data are shared between China, India, Pakistan, and Afghanistan. It is not possible, however, for a single state to engage in science or disaster diplomacy and to negotiate a data-sharing mechanism to improve the accuracy of medium to long range EWS. Cooperation is required. Due to complicated water use issues negotiated by the World Bank for the Indus Basin Treaty between India and Pakistan, any sharing of data between China, India, and Pakistan in pursuance of statedriven international cooperation under the guidance of SFDRR is a lofty dream.

A multilevel risk governance approach differs from a top-down, technocratic model in that, instead of pinning primary responsibility on state governments and international bilateral or multilateral donor agencies, it engages local communities, regional authorities, and transboundary 
partnerships in collaborative agreements. In this framework, subnational or transnational authorities can be empowered through persistent allocation of investments and resources. Application of a multilevel risk governance approach to implant DRR into development and planning processes shifts power to local community scale market and nonmarket dynamics. This shift in focus determines what actually takes place on the ground, that is, whether wetlands are conserved or destroyed; whether roads and bridges are built on flood zones or not; whether intensive agriculture is developed in drought prone areas or not. Larger scale interest groups and entities can and do influence such local scale decision-making processes, as documented in Zia et al. (2011) and Zia (2013). However, empowered local scale communities in a pluralistic and multilevel risk governance system can push back against top-down decisions from larger scale groups and entities. A true test of SFDRR implementation will be if investments and resources are allocated in such a way that local vulnerable communities are empowered to increase community resilience and DRR with or without the support of relevant national and regional entities. The SFDRR highlights the importance of people-centered, bottom-up processes, although empowerment of local vulnerable communities through democratic and participatory processes cannot be achieved by paying lip service in the framework. The tension between top-down and bottom-up governance needs to be tackled upfront through the identification of multilevel risk governance means of implementation.

\section{Conclusions and Recommendations for Improving the "Means of Implementation"/ Multilevel Governance of Sendai Framework}

In their evaluation of scientific and policy rationale behind climate change-related capacity building efforts in developing countries, Glantz (2003) and Glantz and Adeel (2000) maintain that adaptation to climate change-influenced hazards, such as floods, droughts, and heat waves, is perhaps the most important mechanism developing societies need to effectively respond to climatic changes. Socioeconomic and political systems must respond at multiple governance levels, from the individual household to the national, regional, and global. In South Asia and the African Sahel, for example, floods and droughts, respectively, are among the most important natural factors affecting local livelihoods. Although the SFDRR includes people-centered, bottom-up rhetoric, it lacks explicit means of implementation for governance structures that incorporate people-centered, bottom-up design. A business-asusual, top-down implementation of SFDRR, operating through donor-driven programs and projects that do not strategically incorporate local communities through multilevel risk governance institutions, will not likely change the increasing trend of disasters. Effective DRR for improved water and food security in developing countries, such as in the Indus Basin and the African Sahel region, requires more than technocentric approaches that set up expensive tech-driven monitoring and EWS. To improve societal outcomes, a fundamental transformation in the conceptualization of multilevel governance is needed to change the sources and beneficiaries of the "means of implementation" for the DRR strategies identified in SFDRR. This transformation will require design of EWS that explicitly incorporate the decision-making contexts and risk perceptions of local communities in the face of known hydrometeorological hazards. As end-users of the EWS, communities should be engaged and consulted to ensure the design of systems for optimal local relevance and use. Deliberate channels of information need to be incorporated throughout the system to ensure dissemination of information, including opportunities for feedback. To achieve this, investment allocations should be balanced to support monitoring/EWS and the local-level, land-use development and decision-making processes of vulnerable communities. The incorporation of a balanced multilevel risk governance approach to the implementation of SFDRR, as proposed in this article, would dramatically improve progress towards attaining the 2030 DRR targets identified in SFDRR.

Acknowledgments We gratefully acknowledge funding from the National Science Foundation for EPS-1101317 project on "Research on Adaptation to Climate Change" and NSF-SESYNC/NIMBIOS DBI-1052875 project on "Integrating Human Risk Perception of Global Climate Change into Dynamic Earth System Models."

Open Access This article is distributed under the terms of the Creative Commons Attribution 4.0 International License (http://creativecommons.org/licenses/by/4.0/), which permits unrestricted use, distribution, and reproduction in any medium, provided you give appropriate credit to the original author(s) and the source, provide a link to the Creative Commons license, and indicate if changes were made.

\section{References}

Alfieri, L., P. Salamon, F. Pappenberger, F. Wetterhall, and J. Thielen. 2012. Operational early warning systems for waterrelated hazards in Europe. Environmental Science \& Policy 21: 35-49.

Ardalan, A., K. Naieni, M.-J. Kabir, A. Zanganeh, A. Keshtkar, M. Honarvar, H. Khodaie, and M. Osooli. 2009. Evaluation of Golestan Province's early warning system for flash floods, Iran, 2006-2007. International Journal of Biometeorology 53(3): $247-254$

Bailey, R. 2013. Managing famine risk: Linking early warning to early action. A Chatham House report. London: Royal Institute of International Affairs. 
Basher, R. 2006. Global early warning systems for natural hazards: Systematic and people-centered. Philosophical Transactions of the Royal Society A 364(1845): 2167-2182.

Bohle, H., T. Downing, and M. Watts. 1994. Climate change and social vulnerability: Toward a sociology and geography of food insecurity. Global Environmental Change 4(1): 37-48.

Boyd, E., R. Cornfornth, P. Lamb, A. Tarhule, M. Issa Lélé, and A. Brouder. 2013. Building resilience to face recurring environmental crisis in African Sahel. Nature Climate Change 3(7): 631-637.

Brown, O., A. Hammill, and R. Mcleman. 2007. Climate change as the 'new' security threat: Implications for Africa. International Affairs 83(6): 1141-1154.

Challinor, A., T. Wheeler, P. Craufurd, and A. Kassam. 2007. Assessing the vulnerability of food crop systems in Africa to climate change. Climatic Change 83(3): 381-399.

Davis, M. 2002. Late Victorian holocausts: El Niño, famines, and the making of the third world. New York: Verso.

Fakhruddin, S. 2014. Applications of medium range probabilistic flood forecast for societal benefits: Lessons learnt from Bangladesh. In Reducing disaster: Early warning systems for climate change, ed. Z. Zommers, and A. Singh, 167-183. Dordrecht: Springer.

Funk, C., M. Dettinger, J. Michaelson, J. Verdin, M. Brown, M. Barlow, and A. Hoell. 2008. Warming of the Indian Ocean threatens eastern and southern Africa, but could be mitigated by agricultural development. Proceedings of the National Academy of Sciences of the United States of America 105(32): 11081-11086.

Glantz, M.H. 1992. Global warming and environmental change in sub-Saharan Africa. Global Environmental Change 2(3): 183-204.

Glantz, M.H. (ed.). 1999. Creeping environmental problems and sustainable development in the Aral Sea basin. Cambridge: Cambridge University Press.

Glantz, M.H. 2003. Climate affairs: A primer. Washington DC: Island Press.

Glantz, M.H., and Z. Adeel. 2000. Climate affairs as a nextgeneration environmental science. Global Environmental Change 10(1): 81-85.

Guston, D. 2001. Boundary organizations in environmental policy and science: An introduction. Science, Technology and Human Values 26(4): 399-408.

Hasan, S.S., and S.S.Z. Zaidi. 2012. Flooded economy of Pakistan. Journal of Development and Agricultural Economics 4(13): 331-338.

Immerzeel, W., L. Van Beek, and M. Bierkens. 2010. Climate change will affect the Asian water towers. Science 328(5984): $1382-1385$.

Intrieri, E., G. Gigli, F. Mugnai, R. Fanti, and N. Casagli. 2012. Design and implementation of a landslide early warning system. Engineering Geology 147-148: 124-136.

IPCC (Intergovernmental Panel on Climate Change). 2012. Managing the risks of extreme events and disasters to advance climate change adaptation. A special report of working groups I and II of the intergovernmental panel on climate change. Cambridge, UK: Cambridge University Press.

IPCC (Intergovernmental Panel on Climate Change). 2014. Climate change 2014: Impacts, adaptation, and vulnerability. Contribution of Working Group II to the Fifth Assessment Report of the Intergovernmental Panel on Climate Change. Cambridge, UK: Cambridge University Press.

Javid, D.U. 2011. Genesis and effects of religious extremism in Pakistan. International Journal of Business and Social Science 2(7): 282-288
Katz, R.W., and A.H. Murphy (eds.). 1997. Economic value of weather and climate forecasts. Cambridge, UK: Cambridge University Press.

Kelman, I., and M.H. Glantz. 2014. Early warning systems defined. In Reducing disaster: Early warning systems for climate change, ed. Z. Zommers, and A. Singh, 89-108. Dordrecht: Springer.

Komal, R., and A. Faisal. 2015. Linking financial development, economic growth and energy consumption in Pakistan. Renewable and Sustainable Energy Reviews 44: 211-220.

Liu, P., X. Wang, and A. Salisbury. 2009. Tsunami hazard and early warning system in South China Sea. Journal of Asian Earth Sciences 36(1): 2-12.

Marx, B., S. Thomas, and S. Tavneet. 2013. The economics of slums in the developing world. Journal of Economic Perspectives 27(4): 187-210.

Mustafa, D., and A. Sawas. 2013. Urbanisation and political change in Pakistan: Exploring the known unknowns. Third World Quarterly 34(7): 1293-1304.

Plate, E. 2007. Early warning and flood forecasting for large rivers with the lower Mekong as example. Journal of Hydro-Environment Research 1(2): 80-94.

Pozzi, W., J. Sheffield, R. Stefanski, D. Cripe, R. Pulwarty, J.V. Vogt, and R. Westerhoff. 2013. Toward global drought early warning capability: Expanding international cooperation for the development of a framework for monitoring and forecasting. Bulletin of the American Meteorological Society 94(6): 776-785.

Pulwarty, R., and M. Sivakumar. 2014. Information systems in a changing climate: Early warnings and drought risk management. Weather and Climate Extremes 3: 14-21.

Ramanathan, V., C. Chung, D. Kim, T. Bettge, L. Buja, J.T. Kiehl, and M. Wild. 2005. Atmospheric brown clouds: Impacts on South Asian climate and hydrological cycle. Proceedings of the National Academy of Sciences of the United States of America 102(15): 5326-5333.

Rosenzweig, C., A. Iglesias, X.B. Yang, P.R. Epstein, and E. Chivian. 2001. Climate change and extreme weather events: Implications for food production, plant diseases, and pests. Global Change \& Human Health 2(2): 90-104.

Samimi, C., A. Fink, and H. Paeth. 2012. The 2007 flood in the Sahel: Causes, characteristics and its presentation in the media and FEWS NET. Natural Hazards and Earth Systems Science 12(2): 313-325.

Singh, D., M. Tsiang, B. Rajaratnam, and N. Diffenbaugh. 2014. Observed changes in extreme wet and dry spells during the South Asian summer monsoon season. Nature Climate Change 4: 456-461.

Spahn, H., M. Hoppe, H. Vidiarina, and B. Usdianto. 2010. Experience from 3 years of local capacity development for tsunami early warning in Indonesia: Challenges, lessons and the way ahead. Natural Hazards and Earth System Sciences 10(7): 1411-1429.

Taubenböck, H., N. Goseberg, N. Setiadi, G. Lämmel, F. Moder, M. Oczipka, and R. Klein. 2009. "Last-Mile" preparation for a potential disaster: Interdisciplinary approach towards tsunami early warning and an evacuation information system for the coastal city of Padang, Indonesia. Natural Hazards and Earth Systems Science 9(4): 1509-1528.

Thieler, J., J. Bartholmes, M.-H. Ramos, and A. de Roo. 2009. The European flood alert system. Part 1: Concept and development. Hydrology and Earth Systems Science 12: 125-140.

Thomalla, F., and R. Larsen. 2010. Resilience in the context of tsunami early warning systems and community disaster preparedness in the Indian Ocean region. Environmental Hazards 9(3): 249-265.

Thomson, M., F. Doblas-Reyes, S. Mason, R. Hagedorn, S. Connor, T. Phindela, A. Morse, and T. Palmer. 2006. Malaria early 
warnings based on seasonal climate forecasts from multi-model ensembles. Nature 439(7076): 576-579.

Traore, S., A. Ali, S. Tinni, M. Samake, I. Garba, I. Maigari, A. Alhassane, A. Samba, et al. 2014. AGRHYMET: A drought monitoring and capacity building center in the West Africa Region. Weather and Climate Extremes 3: 22-30.

Turner, A., and H. Annamalai. 2012. Climate change and the South Asian summer monsoon. Nature Climate Change 2(8): 587-595.

Ueda, H., A. Iwai, K. Kuwako, and M. Hori. 2006. Impact of anthropogenic forcing on the Asian summer monsoon as simulated by eight GCMs. Geophysical Research Letters. doi:10.1029/2005GL025336.

UNISDR (United Nations International Strategy for Disaster Reduction). 2005. Hyogo framework for action 2005-2015: Building the resilience of nations and communities to disasters. http://www. unisdr.org/we/inform/publications/1037. Accessed 5 May 2015.

UNISDR (United Nations International Strategy for Disaster Reduction). 2015. Sendai framework for disaster risk reduction 2015-2030. Geneva: UNISDR.

van Aalst, M. 2006. The impacts of climate change on the risk of natural disasters. Disasters 30(1): 5-18.
Zia, A. 2012. Land use adaptation to climate change: Economic damages from land-falling hurricanes in the Atlantic and gulf states of the USA, 1900-2005. Sustainability 4(5): 917-932.

Zia, A. 2013. Post-Kyoto climate governance: Confronting the politics of scale, ideology and knowledge. London: Rutledge.

Zia, A., and M.H. Glantz. 2012. Risk zones: Comparative lesson drawing and policy learning from flood insurance programs. Journal of Comparative Policy Analysis: Research and Practice 14(2): 143-159.

Zia, A., and K. Hameed. 2014. Politics of conflict in Pakistan's tribal areas: Vulnerability reduction in violence-prone complex adaptive systems. In Middle East conflicts and reforms, ed. M.M. Aman, and M.J.P. Aman, 223-236. Washington, DC: Policy Studies Organization/Westphalia Press.

Zia, A., P. Hirsch, A. Songorwa, D.R. Mutekanga, S. O’Connor, T. McShane, and B. Norton. 2011. Cross-scale value trade-offs in managing social-ecological systems: The politics of scale in Ruaha National Park, Tanzania. Ecology and Society 16(4). Article no. 7. 